\title{
Crotalus oreganus concolor: Envenomation Case with Venom Analysis and a Diagnostic Conundrum of Myoneurologic Symptoms
}

\author{
Daniel E. Keyler, PharmD ${ }^{1}$; Vinay Saini, MD ${ }^{2}$; Mark O’Shea, Prof. ${ }^{3}$; Jeff Gee, EMT ${ }^{4}$; \\ Cara F. Smith, MS ${ }^{5}$; Stephen P. Mackessy, $\mathrm{PhD}^{5}$ \\ ${ }^{1}$ Department of Experimental \& Clinical Pharmacology, University of Minnesota, Minneapolis, MN; ${ }^{2}$ Mimbres Memorial Hospital, Deming, New \\ Mexico; ${ }^{3}$ Faculty of Science and Engineering, University of Wolverhampton, Wolverhampton, UK; ${ }^{4}$ Portal Rescue, Portal, AZ; ${ }^{5}$ School of Biological \\ Sciences, University of Northern Colorado, Greeley, $\mathrm{CO}$
}

\begin{abstract}
A case of midget-faded rattlesnake (Crotalus oreganus concolor) envenomation of an adult male professional herpetologist occurred in a rural setting and resulted in an array of venom induced myoneurologic symptoms. The patient experienced blurry vision, total body paresthesia, dyspnea, chest tightness, and waves of spastic muscle movements of the hands and feet that resembled tetany. It was not apparent whether these symptoms were potentially venom induced or were related to stress-induced physiologic responses. Local envenomation effects were minimal, and coagulation parameters remained within normal limits. Antivenom was not administered per patient concerns related to a history of acute allergic reactions to antivenom. Venom was collected from the Crotalus oreganus concolor responsible for the bite, and analysis revealed the presence of high levels of myotoxins (SR calcium pump antagonists) and concolor toxin, a presynaptic neurotoxin that can have myotoxic effects and cause respiratory paralysis; several serine proteinases associated with coagulopathies were also present in the venom profile.
\end{abstract}

Keywords: rattlesnake, snakebite, hyperventilation, carpopedal, alkalemia, hypocalcemia

\section{Introduction}

The midget-faded rattlesnake (Crotalus oreganus concolor) is an uncommon, small (50-65 cm total body length) subspecies originally assigned to the Crotalus viridis complex and currently recognized as a subspecies in the Crotalus oreganus clade. ${ }^{1,2}$ It is indigenous to a restricted geographic range of the Colorado Plateau that includes west central Colorado, the Colorado and Green River basins, eastern Utah, southwestern Wyoming, and extreme northern Arizona. ${ }^{3-5}$

Platform presentation by Daniel E Keyler at the Venom Week VI Meeting, March 14, 2018; Texas A\&M University, Kingsville, Texas, USA.

Corresponding author: Daniel E. Keyler, PharmD, Department of Experimental \& Clinical Pharmacology, 7-115 Weaver-Densford Hall, 308 Harvard St. S.E., University of Minnesota, Minneapolis, Minnesota, 55455; e-mail: keyle001@umn.edu.

Submitted for publication May 2019.

Accepted for publication December 2019.
Crotalus oreganus concolor venom studies have revealed the presence of a potent lethal toxin, antigenically similar to Mojave toxin. ${ }^{6,7}$ It has been determined to be one of the most lethal crotaline venoms, nearly equal in toxicity to Crotalus durissus terrificus and Crotalus scutulatus scutulatus venoms based on murine lethality experiments. ${ }^{8}$ In addition, Crotalus oreganus concolor venom lethality is reported to range from 10- to 30-fold greater than multiple other crotaline species. ${ }^{8,9}$ A presynaptic phospholipase $A_{2}-\beta$-neurotoxin (concolor toxin) and nonenzymatic peptide myotoxins have been identified as major venom components. ${ }^{9-12}$

Envenomation of humans by Crotalus oreganus concolor is rare, and the case reported here illustrates what clinically appeared to be possible venom-induced myoneurologic symptoms that were confounded in interpretation by physiologic stresses. Analysis of venom from the Crotalus oreganus concolor responsible in this case suggested a possible correlation between specific venom components and several observed clinical symptoms. 

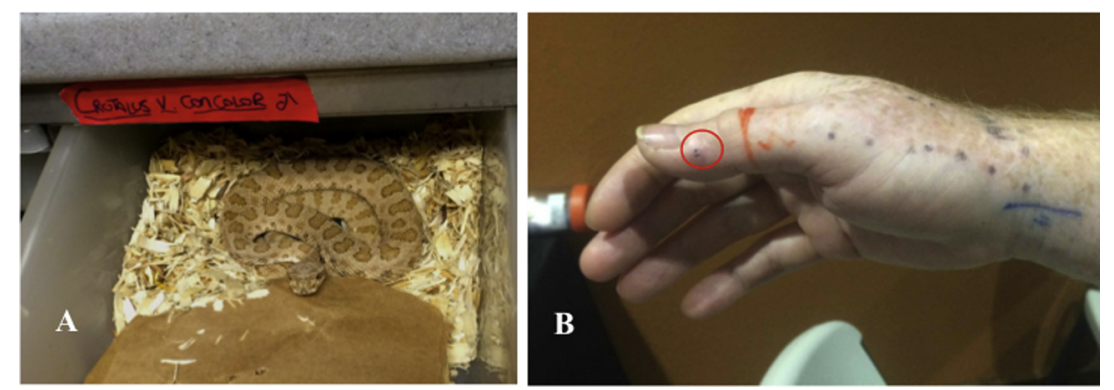

Figure 1. A, The midget faded rattlesnake (Crotalus oreganus concolor) responsible for the bite, in its housing drawer enclosure from which it struck, imparting a single fang puncture to the patient. B, Single fang puncture into the distal phalangeal region of the right thumb.

\section{Case Presentation}

A healthy 61-y-old male professional herpetologist sustained a bite from a captive (wild caught) adult male Crotalus oreganus concolor (Figure 1A). Patient history included prior crotaline envenomation from Crotalus horridus, Crotalus horridus atricaudatus (subspecies recognized at the time of the bite), and Crotalus durissus ruruima. Treatments involved Wyeth anticrotalic antivenoms and Instituto Butantan anticrotalico, with anaphylactic reactions having occurred. Patient medication history included migraine headache prescriptions (rizatriptan, atenolol, and amitriptyline).

The incident took place in a remote facility, and the bite occurred as the snake was being removed from a drawertype housing unit, resulting in a single fang puncture into the right thumb (Figure 1B). The patient immediately experienced generalized "pins and needles" sensations in the bitten thumb that rapidly progressed to pain, followed by tingling of the lips and a feeling of chest tightness. Within 15 min the patient reported total body tingling. The first responder found the patient resting supine on the floor and reported the patient did not appear anxious or agitated, with no obvious signs of hyperventilation (20 breaths $\left.\cdot \min ^{-1}\right)$. The patient described feeling like he was "wearing a clay mask and a hat with hat band one size too small constricting around my forehead." The affected limb was splinted for immobilization during a 1-h ground ambulance transport to the helispot and subsequent 45min helicopter flight to a rural hospital. During ground transport, the patient reported breathing difficulty, and supplemental oxygen was provided via nasal cannula. Tightening of the tongue, blurred vision, and difficulty speaking were also experienced. Three distinct waves of transient neuromuscular spasms associated with inspirational weakness ensued. Spastic simultaneous contractures of first the left hand and then to a lesser degree the right (bitten) hand and foot/toes occurred, followed by a third wave that involved the left forearm, lower leg, and foot. The first responder described these waves as severe, tetany-like, spastic muscle movement (Figure 2A). The patient was alert and oriented; blood pressure was normal by sphygmomanometer/cuff (113/72 $\mathrm{mm} \mathrm{Hg}$ ), and pulse was normal by palpitation $\left(69\right.$ beats $\cdot \min ^{-1}$ ) (Figure $\left.2 \mathrm{~B}\right)$.

Approximately $2.5 \mathrm{~h}$ postbite the patient arrived to the emergency department, and the myoneurologic symptoms had abated. Examination revealed a single fang puncture in the distal phalangeal region of the right thumb and swelling that extended proximally to the thenar eminence. Chemistry panel, complete blood count, electrolytes, coagulation, and hematologic parameters were within normal limits, excepting a slightly elevated D-dimer $\left(566 \mathrm{ng} \cdot \mathrm{mL}^{-1}\right.$ FEU; reference laboratory range $\left.190-490 \mathrm{ng} \cdot \mathrm{mL}^{-1} \mathrm{FEU}\right)$ and elevated creatine kinase $(\mathrm{CK}) 3394 \mathrm{U} \cdot \mathrm{L}^{-1}$ (reference laboratory range $\left.22-198 \mathrm{U} \cdot \mathrm{L}^{-1}\right)$.

Over the following $24 \mathrm{~h}$, there was a small decline in total serum calcium from $8.8 \mathrm{mg} \cdot \mathrm{dL}^{-1}(3 \mathrm{~h})$ to 7.7 $\mathrm{mg} \cdot \mathrm{dL}^{-1}(22 \mathrm{~h})$ (reference laboratory range $8.5-10.1$ $\mathrm{mg} \cdot \mathrm{dL}^{-1}$ ) and a corresponding slight decline in serum albumin from $4.2 \mathrm{~g} \cdot \mathrm{dL}^{-1}(3 \mathrm{~h})$ to $3.5 \mathrm{~g} \cdot \mathrm{dL}^{-1}(22 \mathrm{~h}$ ) (reference laboratory range $\left.3.4-5.0 \mathrm{~g} \cdot \mathrm{dL}^{-1}\right)$. There was no evidence of bleeding at any time. Swelling spread proximally to midforearm over the first $3 \mathrm{~h}$, but local pain had lessened. Medical staff observed weak patient total body strength with poor coordination, requiring walking frame assistance. There was no evidence of compartment syndrome. Despite indications for antivenom, its administration was declined by the patient because of anaphylactic reactions from previous antivenom treatments.

The patient was observed for another $6 \mathrm{~h}$ and discharged at $25 \mathrm{~h}$ postbite $(22 \mathrm{~h}$ postadmission) in stable condition. At $24 \mathrm{~h}$ after discharge, the patient remained weak but could walk without assistance. Myalgia in the right arm and generalized weakness persisted for several days. At 3-wk follow-up, the bitten thumb skin had sloughed and thumb numbness persisted, but other local symptoms had resolved completely and all laboratory studies were unremarkable. Venom from the responsible Crotalus oreganus concolor was collected for assay and analysis of venom components and their potential correlation to observed symptoms. 

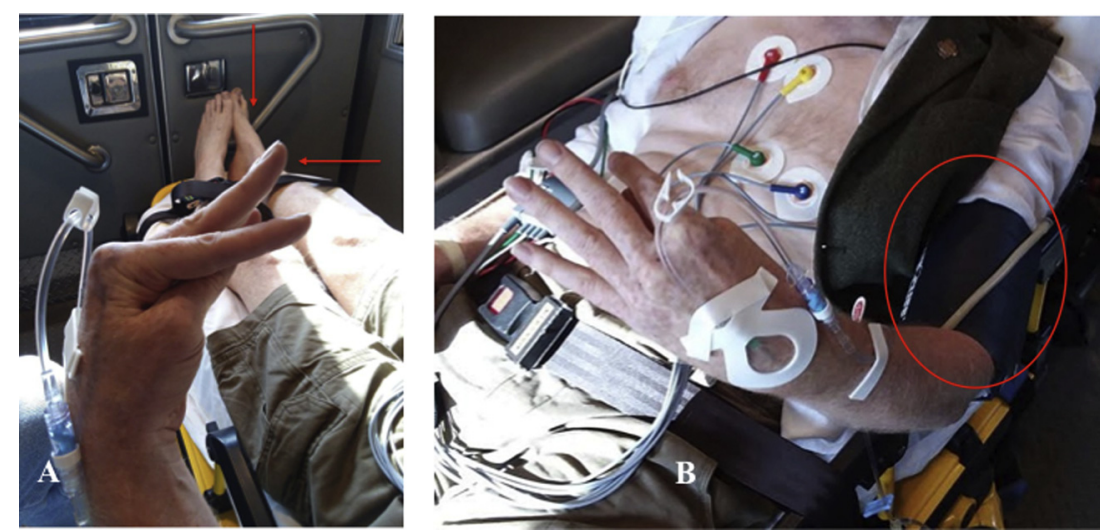

Figure 2. A, Tetany-like spasms showing flexion of the hands and extension of the feet (carpopedal spasms) that began 30 min after the bite. Three waves of approximately $10 \mathrm{~min}$ each, $20 \mathrm{~min}$ apart, were observed. B, Blood pressure and pulse were normal to low as measured by palpitation and the sphygmomanometer/cuff placed on the contralateral arm.

\section{METHODS}

Venom was extracted manually from the Crotalus oreganus concolor responsible for the bite approximately $4 \mathrm{~d}$ after the bite and centrifuged to pellet the cell debris, and the supernatant was lyophilized (fluid yield $120 \mu \mathrm{L} ; \approx 27 \mathrm{mg}$ dry venom). Lyophilized venom was solubilized in phosphatebuffered saline $\left(8.0 \mathrm{mg} \cdot \mathrm{mL}^{-1}\right)$, and $200 \mu \mathrm{L}(1.6 \mathrm{mg})$ was subjected to reversed-phase high-performance liquid chromatography (RP-HPLC) as reported previously; 1-min fractions were collected and lyophilized. ${ }^{13}$ Toxins were identified from the known elution profiles of purified toxins and quantified via peak area integration (percentage total area).

HPLC fractions were also subjected to polyacrylamide gel electrophoresis (SDS-PAGE) under reducing conditions to identify chromatogram peaks. ${ }^{13}$ Crude venom was assayed for protein content via Pierce BCA assay and for 6 enzyme activities common to rattlesnake venoms. ${ }^{10,14}$ These data were used in conjunction with HPLC chromatogram data to identify the protein families present and their relative abundance in the venom.

\section{DISCUSSION}

Our patient's symptoms illustrate a potential diagnostic conundrum clinicians may face in cases of snakebite envenomation: What symptoms might be venom-induced effects, and what symptoms might be related to stress-induced physiologic responses? Our patient experienced generalized paresthesia, blurred vision, waves of spastic, tetany-like symptoms of the hands and feet (carpopedal spasms), breathing difficulties, numbness, and generalized weakness that persisted for days, all symptoms consistent with venom-induced effects reported in other cases of North American rattlesnake envenomation, including by Crotalus oreganus concolor. ${ }^{9,15-17}$ However, in our patient, the tetany-like carpopedal spasms may not have been venom induced, but instead from patient anxiety-induced hyperventilation or sphygmomanometer cuff inflation. ${ }^{18,19}$ Crotalus oreganus concolor venom contains myotoxic and neurotoxic components capable of eliciting neurotoxic symptoms. ${ }^{9,10,12}$ Purified Crotalus oreganus concolor venom toxins injected into mice elicit myotoxic effects of rapid ataxia, hind limb extension, and respiratory distress. ${ }^{7,20}$ Collectively, symptoms in the present case combined with the interpretation of the venom analysis for the inflicting snake provide for interesting discussion.

Venomous snakebite can trigger significant anxiety, leading to an autonomic response of hyperventilationinduced alkalemia with consequent precipitation of hypocalcemia, resulting in symptoms of breathlessness and paresthesia of the face and hands, although blood pressure remains normal. ${ }^{18}$ Tetany-like symptoms of painful sharp involuntary flexion of the wrist and ankle joints (carpopedal spasms), cramps, and muscle twitching may be clinically misleading. These physiologic responses are due to decreased extracellular ionized calcium, resulting in hyperexcitability of muscles and nerves. ${ }^{18}$ Ionized serum calcium was not measured in our patient; however, the patient was not observed to be tachypnic, although hyperventilation may occur via slow deep breathing. Hypocalcemic tetany of the lower extremities has been reported in a case of Crotalus scutulatus envenomation with minimal coagulopathy, but this was thought to have been subsequent to rhabdomyolysis. ${ }^{21}$ Our patient had normal blood pressure and may have deeply hyperventilated to the point of respiratory alkalosis followed by hypocalcemic tetany. The carpopedal symptoms fit the profile of stress-related physiologic responses, which were considered a contributing root cause.

Blood pressure measurement via sphygmomanometer with an inflatable cuff was used to monitor our patient's blood pressure during ambulance transport. Cuff inflation, in conjunction with hyperventilation-induced hypocalcemia, likely triggered a classic Trousseau sign. ${ }^{19}$ Cuff 


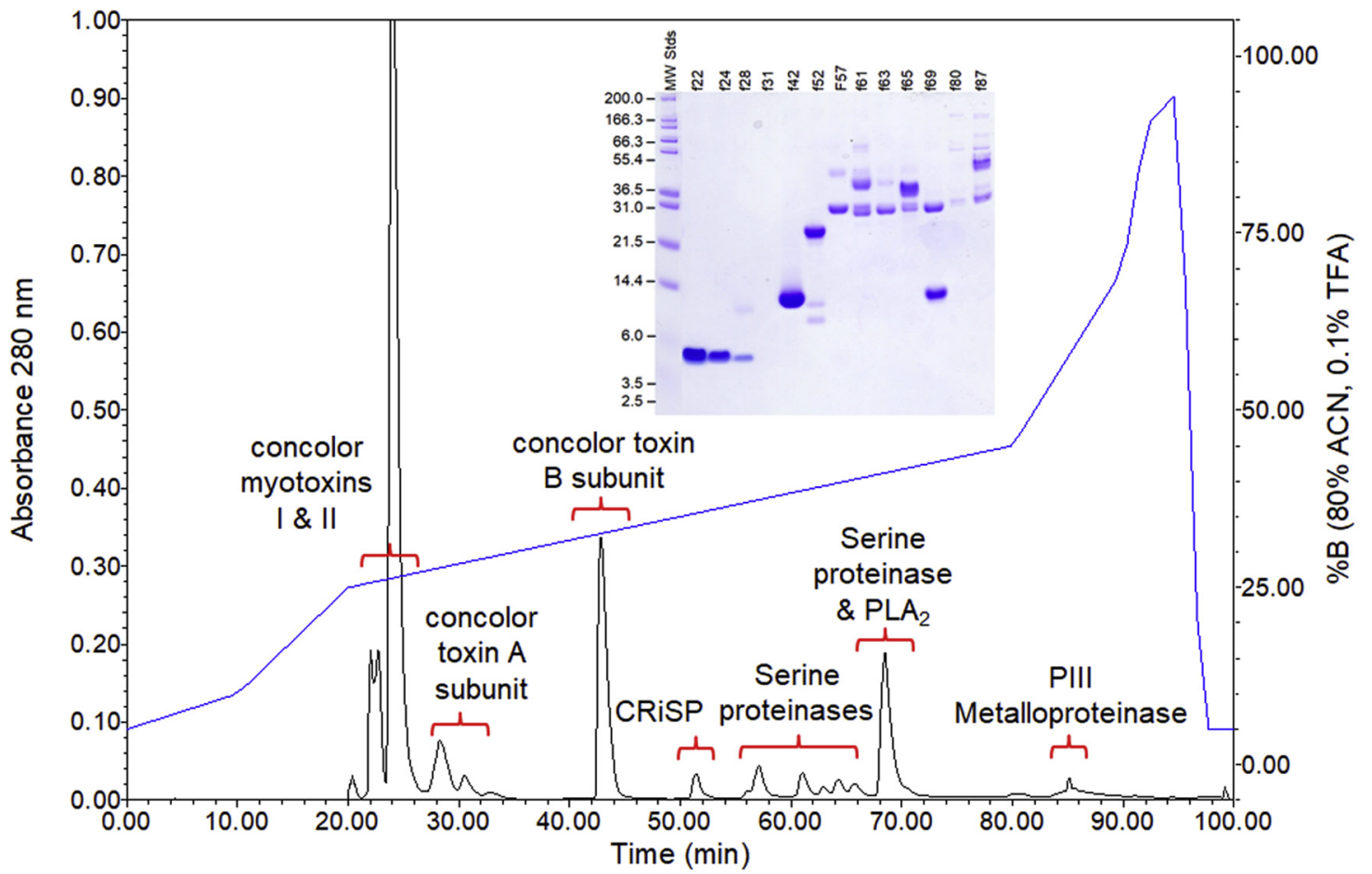

Figure 3. Reversed-phase high-performance liquid chromatography chromatogram of Crotalus oreganus concolor venom, $1.6 \mathrm{mg}$ in $200 \mu \mathrm{L}$ phosphatebuffered saline. Identification of peaks are based on SDS-PAGE and enzyme activity assays. Inset: reducing SDS-PAGE of indicated high-performance liquid chromatography fractions. CRiSP, cysteine-rich secretory protein.

inflation to greater than the mean arterial pressure can result in the hand adopting a posture of metacarpophalangeal joint flexion with the interphalangeal joints of the fingers and thumb extended so that the thumb is in an opposing posture, as observed in our patient (Figure 2B). This phenomenon has been reported in 1 to $4 \%$ of healthy individuals but has not been reported to be associated with cases of snakebite envenomation. ${ }^{19}$ Although Crotalus oreganus concolor myotoxic venom components can induce muscle contractile activity, causing rapid tetany-like hind limb hyperextension in mice (a symptom somewhat similar to the extension of the ankles, feet, and toes observed in our patient), this symptom was likely a stress-induced response rather than venom induced ${ }^{20,22}$

Our patient's other myoneurologic symptoms of paresthesia, respiratory distress, and total body weakness may have been related to the high myotoxin content and concolor toxin in the Crotalus oreganus concolor's venom (Figure 3 , Table 1). Studies in mice injected with Crotalus oreganus concolor venom showed they died from rapid respiratory failure, suggesting that venom may have contributed to our patient's respiratory difficulty, as has been reported to occur after $C$ scutulatus, $C$ cerastes, $C$ oreganus helleri, and $C$ horridus envenomation. ${ }^{16,17,23,24}$

Venom was delivered to our patient via a single fang puncture, and it is reasonable to assume it was not a maximum dose; this is a potential reason for the reduced severity and duration of symptoms. Neurotoxic effect duration after snake envenomation is highly variable. ${ }^{25}$ The short duration of myoneurologic actions in our patient may have been related to dose-dependent pharmacokinetics or pharmacokinetic metabolic actions on a responsible toxin.

Myokymia has been reported after envenomation by Crotalus oreganus concolor and other North American rattlesnakes. ${ }^{15,26,27}$ In our patient, the periodic episodes of tetany-like carpopedal spasms were distinctly different from myokymia or fasciculations. ${ }^{15,27}$

Crotaline envenomation can result in hematologic effects ranging from mild to severe coagulopathy and

Table 1. Composition of Crotalus oreganus concolor venom based on percent area of reversed-phase high-performance liquid chromatography peaks and SDS-PAGE

\begin{tabular}{ll}
\hline Protein family & Percent \\
\hline Myotoxin I and II & 60 \\
Concolor toxin subunit B & 15 \\
Snake venom serine proteinases & 9 \\
Concolor toxin subunit A & 6 \\
Phospholipase A2 (acidic) & 6 \\
Unidentified & 3 \\
Snake venom metalloproteinase (P-III) & 1 \\
\hline
\end{tabular}

Note that myotoxins I and II comprise the majority of venom proteins. 
Table 2. Assays of Crotalus oreganus concolor venom for enzyme activities common to rattlesnake venoms

\begin{tabular}{lll}
\hline Enzyme assayed & Specific activity & Relative activity \\
\hline Phospholipase $\mathrm{A}_{2}\left(\mathrm{nmol}\right.$ product $\cdot \mathrm{min}^{-1} \cdot \mathrm{mg}^{-1}$ ) & 25.4 & $\downarrow$ \\
Azocasein metalloproteinase $\left(\mathrm{Abs} 342 \mathrm{~nm} \cdot \mathrm{min}^{-1} \cdot \mathrm{mg}^{-1}\right.$ ) & 0.01 & $\downarrow \downarrow$ \\
Kallikrein-like (nmol product $\cdot \mathrm{min}^{-1} \cdot \mathrm{mg}^{-1}$ ) & 970.9 & $\uparrow \uparrow$ \\
Thrombin-like (nmol product $\cdot \mathrm{min}^{-1} \cdot \mathrm{mg}^{-1}$ ) & 1388.8 & $\uparrow \uparrow$ \\
Phosphodiesterase (Abs 400 $\mathrm{nm} \cdot \mathrm{min}^{-1} \cdot \mathrm{mg}^{-1}$ ) & 1 & $\uparrow$ \\
L-amino acid oxidase (nmol product $\left.\cdot \mathrm{min}^{-1} \cdot \mathrm{mg}^{-1}\right)$ & 9.7 & $\downarrow$ \\
\hline
\end{tabular}

$\downarrow$, venom activity lower than average; $\uparrow$, venom activity higher than average

Activity levels in the responsible venom relative to averages of 22 taxa of rattlesnakes (Mackessy ${ }^{33}$ ) are also indicated.

neurologic effects ranging from paresthesia to seizures and coma. Consequently, patients can exhibit multiple combinations of clinical manifestations varying in severity. ${ }^{28}$ Thus, the absence of hematologic effects in our patient, in the presence of neurologic symptoms, was not uncharacteristic of rattlesnake envenomation. Neurologic symptoms after $C$ cerastes and $C$ concolor envenomation, without hematologic effects, have been reported..$^{9}$ 15-17

Local wound complications in our patient were modest, including ecchymosis, swelling, pain, and skin sloughing. Elevated CK, a routinely used marker for tissue damage and myonecrosis, has been reported in 2 cases of Crotalus oreganus concolor envenomation (range 1800-17,000 IU $\cdot \mathrm{L}^{-1}$ ) and in the absence of coagulopathic complications. ${ }^{15,29}$

Our patient's elevated CK value $\left(3394 \mathrm{U} \cdot \mathrm{L}^{-1}\right)$ at $22 \mathrm{~h}$ after envenomation was indicative of venom-induced local tissue/muscle damage to the bitten thumb.

Medications may influence snake envenomation symptoms, and our patient's medications (atenolol, rizatriptan, and amitriptyline) have reported adverse effects of blurred vision, numbness, chest tightness, paresthesia, and weakness similar to our patient's symptoms. ${ }^{30,31}$ Our patient reported having no adverse effects to these medications before the bite, suggesting drug/venom interactions were noncontributory to observed symptoms.

Venom analyses of the responsible snake revealed abundant $\mathrm{PLA}_{2}$-based $\beta$ neurotoxin (concolor toxin) and nonenzymatic peptide myotoxins. ${ }^{9,12,32}$ Enzyme analyses revealed the presence of 6 enzymes common to rattlesnake venoms (Table 2); however, their levels varied significantly from averaged values based on 22 taxa of rattlesnakes. ${ }^{33}$ Notably, snake venom metalloproteinase activity (azocasein metalloproteinase) was barely detectable, and this likely was responsible for the lack of hemorrhage, rhabdomyolysis, or inflammation. These very low levels of snake venom metalloproteinase are characteristic of type II venoms, including that of Crotalus oreganus concolor. ${ }^{10}$ Thrombin-like and kallikrein-like serine proteinase activities in the venom were quite high, and thrombin-like activity was nearly twice the average value of many rattlesnake venoms. Because of these high activity levels, coagulopathies including hypofibrinogenemia would have been expected; however, laboratory blood panels did not indicate any form of coagulopathy. Phospholipase $\mathrm{A}_{2}$ levels were moderate but not noteworthy compared to other species; $\mathrm{PLA}_{2}$ activity is sometimes associated with severe inflammation, myotoxicity, and occasionally renal damage/failure. The lack of these symptoms indicates that this acidic $\mathrm{PLA}_{2}$ was not particularly toxic, consistent with similar enzymatic $\mathrm{PLA}_{2}$ S from other species.

RP-HPLC analysis of the venom (Figure 3) indicated the presence of myotoxins I and II, small peptide components common to the venoms of numerous species of rattlesnakes. ${ }^{31}$ In humans, they may be responsible for fasciculations (possibly muscle weakness, both acute and prolonged). ${ }^{25}$ The myotoxin content of this venom was extremely high and comprised $>59 \%$ of the total venom proteins; concolor toxin made up $>21 \%$ of the venom total protein content (Figure 3, Table 1). The combined actions of these 2 protein families, comprising $>80 \%$ of venom proteins, possibly contributed to the rapid paraesthesias and other tetany-like symptoms observed in the patient.

\section{Conclusions}

The case reported here is an interesting academic case in that certain symptoms, similar to previously reported cases of Crotalus oreganus concolor envenomation, may have been a hybridization of anxiety- and stress-induced symptoms combined with venom-induced symptoms. Analyses of ionized calcium and arterial blood gases and a formal neurologic evaluation would have provided for a more comprehensive assessment to confirm or rule out the source of some symptoms. Although the venom profile of the snake involved showed a high myotoxin content, this is unlikely to have played a role in the myoneurologic (carpopedal spasms) symptoms. Thus, the presented case illustrates a diagnostic conundrum, and medical personnel should be cognizant of the potential for confounding symptoms associated with rattlesnake envenomation and interpretation as to their cause. 
Acknowledgments: Appreciation is extended to Professor David Warrell for insightful comments regarding the clinical case.

Author Contributions: Acquisition of case data and analysis of case data (DEK, MO, VS, JG); photo credits: Figure 1 (DEK), Figure 2 (JG); drafting of case and overall manuscript (DEK); acquisition of venom data and analysis of venom data (SPM, CFS); drafting venom analysis portion of manuscript (SPM, CFS); critical revision and approval of final manuscript (DEK, SPM). Financial/Material Support: None.

Disclosures: None.

\section{References}

1. Ashton KG, de Queiroz A. Molecular systematics of the western rattlesnake, Crotalus viridis (Viperidae), with comments on the utility of the D-loop in phylogenetic studies of snakes. Mol Phylogenet Evol. 2001;21(2):176-89.

2. Parker JM, Anderson SH. Ecology and behavior of the midget faded rattlesnake (Crotalus oreganus concolor) in Wyoming. J Herpetol. 2007;41(1):41-51.

3. Woodbury AM. A new rattlesnake from Utah. Bull Unit Utah. 1929;20:1.

4. Woodbury AM. The name Crotalus viridis concolor Woodbury. Copeia. 1958;2:151.

5. Brennan TC, Holycross AT. Crotalus oreganus concolor geographic distribution. Herpetol Rev. 2004;35:190-1.

6. Pool WR, Bieber AL. Characterization of some components of venom from Crotalus viridis concolor). Fed Proc Fed Am Soc Exp Biol. 1980;39(4):1646.

7. Weinstein SA, Minton SA, Wilde CE. The distribution among ophidian venoms of a toxin isolated from the venom of the Mojave rattlesnake (Crotalus scutulatus scutulatus). Toxicon. 1985;23(5):825-44.

8. Glenn JL, Straight R. The midget faded rattlesnake (Crotalus viridis concolor) venom: lethal toxicity and individual variability. Toxicon. 1977;15(2):129-33.

9. Mackessy SP, Williams K, Ashton KG. Ontogenetic variation in venom composition and diet of Crotalus oreganus concolor: a case of venom paedomorphosis? Copeia. 2003;4:769-82.

10. Mackessy SP. Evolutionary trends in venom composition in the western rattlesnakes (Crotalus viridis sensu lato): toxicity vs. tenderizers. Toxicon. 2010;55(8):1463-74.

11. Modahl CM, Mackessy SP. Full-length venom protein cDNA sequences from venom-derived mRNA: exploring compositional variation and adaptive multigene evolution. PLoS Negl Trop Dis. 2016;10(6), e0004587.

12. Pool WR, Bieber AL. Fractionation of midget faded rattlesnake (Crotalus viridis concolor) venom: lethal fractions and enzymatic activities. Toxicon. 1981;19(4):517-27.

13. Smith CF, Mackessy SP. The effects of hybridization on divergent venom phenotypes: characterization of venom from Crotalus scutulatus scutulatus x Crotalus oreganus helleri hybrids. Toxicon. 2016;120:110-23.

14. Smith PK, Krohn RI, Hermanson GT, Mallia AK, Gartner FH, Provenzano MD, et al. Measurement of protein using bicinchoninic acid. Anal Biochem. 1985;150(1):76-85.

15. LoVecchio F, Pizon AF, Wallace KL, Kunkel DB. Myokymia after snake envenomation in Arizona. Wilderness Environ Med. 2005;16(2):116-7.
16. Bosak AR, Ruha AM, Graeme KA. A case of neurotoxicity following envenomation by the sidewinder rattlesnake, Crotalus cerastes. J Med Toxicol. 2014;10(2):229-31.

17. Bush SP, Siedelburg E. Neurotoxicity associated with suspected Southern Pacific rattlesnake (Crotalus viridis helleri) envenomation. Wilderness Environ Med. 1999;10(4):247-9.

18. Mrunalini P, Shaik MS, Nagendra NV. Cramps and tingling: a diagnostic conundrum. Anesth Essays Res. 2014;8(2):247-9.

19. Rehman HU, Wunder S. Trouseau sign in hypocalcemia. CMAJ. 2011;183(8):E498.

20. Ownby CL, Aird SD, Kaiser II . Physiological and immunological properties of small myotoxins from the venom of the midget faded rattlesnake (Crotalus viridis concolor). Toxicon. 1988;26(3):319-23.

21. Bush SP, Jansen PW. Severe rattlesnake evenomation with anaphylaxis and rhabdomyolysis. Ann Emerg Med. 1995;25(6):845-8.

22. Hayes CE, Bieber AL. The effects of myotoxin from midget faded rattlesnake (Crotalus viridis concolor) venom on neonatal rat myotubes in cell culture. Toxicon. 1986;24(2):169-73.

23. Clark RF, Williams SR, Nordt SP, Boyer-Hassen LV. Successful treatment of Crotalid-induced neurotoxicity with a new polyspecific Crotalid Fab antivenom. Ann Emerg Med. 1997;30(1):54-7.

24. Madey JJ, Price AB, Dobson JV, Stickler DE, McSwain SD. Facial diplegia, pharyngeal paralysis, and ophthalmoplegia after a timber rattlesnake envenomation. Pediatr Emerg Care. 2013;29(11):1213-6.

25. Ranawaka UK, Lalloo DG, de Silva HJ. Neurotoxicity in snakebite - the limits of our knowledge. PLoS Negl Trop Dis. 2013;7(10):e2302.

26. Brick JF, Gutmann L, Brick J, Apelgren KN, Riggs JE. Timber rattlesnake venom-induced myokymia: evidence for peripheral nerve origin. Neurology. 1987;37(9):1545-6.

27. Vohra R, Cantrell FL, Williams SR. Fasciculations after rattlesnake envenomations: a retrospective statewide poison control system study. Clin Toxicol (Phila). 2008;46(2):117-21.

28. Dart RC, Hurlbut KM, Garcia R, Boren J. Validation of a severity score for the assessment of crotalid envenomation. Ann Emerg Med. 1996;27(3):321-6.

29. Mebs D, Ehernfeld M, Samejima Y. Local necrotizing effect of snake venoms on skin and muscle: relationship to serum creatine kinase. Toxicon. 1983;21(3):393-404.

30. Schulte J, Kleinschmidt KC, Domanski K, Smith EA, Haynes A, Roth B. Differences between snakebites with concomitant use of alcohol or drugs and single snakebites. South Med J. 2018;111(2):113-7.

31. US Food \& Drug Administration. Drugs. Available at: https://www.fda.gov/Drugs/default.htm. Accessed November $18,2018$.

32. Bieber AL, McParland RH, Becker RR. Amino acid sequences of myotoxins from Crotalus viridis concolor venom. Toxicon. 1987;25(6):677-80.

33. Mackessy SP. Venom composition in rattlesnakes: trends and biological significance. In: Hayes WK, Beaman KR, Cardwell MD, Bush SP, eds. The Biology of Rattlesnakes. Loma Linda, CA: Loma Linda University Press; 2008: 495-509. 